Laboratory of Economics and Management Sant'Anna School of Advanced Studies

Piazza Martiri della Libertà, 33 - 56127 PISA (Italy)

Tel. +39-050-883-343 Fax +39-050-883-344

Email: lem@sssup.it Web Page: http://www.sssup.it/ LEM/

\title{
LEM
}

Working Paper Series

\section{The Economics of}

\section{Strategic Opportunity}

* Institute of International Business Stockholm School of Economics

$†$ Dept. of Management, The Wharton School 


\title{
The Economics of Strategic Opportunity
}

\author{
Jerker Denrell \\ Institute of International Business \\ Stockholm School of Economics \\ Box 6501, SE-113 83 Stockholm Sweden \\ Jerker.Denrell@hhs.se \\ Christina Fang \\ Department of Management \\ 2000 Steinberg Hall - Dietrich Hall \\ The Wharton School \\ Philadelphia PA 19104-6370 \\ cafang@wharton.upenn.edu \\ Sidney G. Winter \\ Department of Management \\ 2000 Steinberg Hall - Dietrich Hall \\ The Wharton School \\ Philadelphia PA 19104-6370 \\ winter@wharton.upenn.edu
}

February 2003

We thank Daniel Levinthal for his contribution to prior work we draw on here. We are also grateful for comments from participants at the strategy conference at the Cox School of Business, and to David Hoopes for editorial suggestions. Winter acknowledges research support from the Reginald H. Jones Center of the Wharton School. All errors remain our own. 


\begin{abstract}
As emphasized by Barney (1986), any explanation of superior profitability must account for why the resources supporting such profitability could have been acquired for a price below their rent generating capacity. Building upon the literature in economics on coordination failures and incomplete markets, we suggest a framework for analyzing such strategic factor market inefficiencies. Our point of departure is that a strategic opportunity exists whenever prices fail to reflect the value of a resource's best use. This paper examines the challenges of imputing a resource's value in the absence of explicit price guidance and suggests the likely characteristics of strategic opportunities. Our framework also suggests that the discovery of strategic opportunity is often a matter of "serendipity" and access to relevant idiosyncratic resources. This latter observation provides prescriptive advice, although the analysis also explains why more detailed guidance has to be firm specific.
\end{abstract}




\section{Introduction}

Given that firms are distinguished by the resources they command, and that those resources must in some ultimate sense have been acquired through purchase, how could it happen that the purchase prices are sufficiently favorable to support superior profitability (Barney 1986)? Barney sets forth what might be called the "bad news" about resource valuation: in general it is difficult to purchase things for less than they are worth. The interests of both the seller and rivals should stand in the way of such an accomplishment. This paper sets forth the good news about resource valuation: our stance is that "the good news is that the bad news is wrong". ( Or at least, the bad news is valid only within its proper sphere.)

Although Barney did not make explicit reference to the efficient markets hypothesis, his vigorous statement of the bad news for strategy clearly has much in common with the (semistrong) EMH: unless you have superior (inside) information, your only chance of "beating the market" is the same chance of having good luck that everybody has. This argument seems to put hurdles in the way of anyone who would presume to offer strategic advice, just as the EMH challenges anyone who presumes to offer stock tips at a positive price. We argue, however, that this perspective greatly overstates the degree to which market processes establish the prices of strategically significant resources. By so doing, it understates the possibilities for uncovering "abnormally profitable" courses of action. Barney's acknowledged exceptions to the bad news proposition -- "superior information" and "luck" - are more broadly relevant than they may appear.

The crucial missing element in the resource valuation story is the idiosyncratic position of the individual firm. The view of each firm is shaped by its own existing resources and information, including its ability to assess the resources of other firms, and is to that extent unique. The more distinctive the view, the more likely that such a view can encompass valuable opportunities not similarly visible to other firms - implying at least a temporary advantage for the firm that identifies the opportunity. In a changing environment, there is continuing renewal of each firm's view of the opportunities that are differentially suited to it, even without explicit effort to this end by the firm itself. Whether the opportunities seen are actually seized is, however, an important question. We argue that the discovery of a valuable strategic opportunity is often a matter of "serendipity" in the strict sense - not just luck, but effort and luck joined by alertness and flexibility.

To appreciate these points it is necessary to break out of the equilibrium mindset that dominates so much of economic theory - including, of course, the EMH. Central to our argument is the proposition that the economic analysis of strategic opportunity at the firm level is a problem that is intimately connected to the analysis of coordination failures in market systems. In particular, strategic opportunities remain in situations where market prices do not reflect the value of resources in their best use. In developing our arguments, we have the advantage of being able to draw on some recent contributions in economic theory that offer novel perspectives on the problem of coordination failure, particularly Makowski and Ostroy (1995) and Matsuyama (1997). ${ }^{2}$

\footnotetext{
${ }^{1}$ This nice phrase is the title of a book by Ben J. Wattenberg (1984).

2 This problem, however, has a substantial previous history in several branches of the economics literature, particularly economic development (Scitovsky 1954, Hirschman 1958) and Austrian Economics (Hayek 1945, Kirzner 1973, 1997). In addition, of course, there is a stream in the strategic management literature that explores the
} 
Our argument proceeds as follows. In the next section, we lay out the terms of our discussion, which is not by any means in perfect alignment with the usual treatment of these issues in strategic management. We then in Section 3 turn to the issue of the completeness of markets, as it is framed in economics, and explain its relationship to the assessment of strategic opportunities. Section 4 explores the knowledge and learning challenges facing entrepreneurs who attempt to value resources in the typical scenario of incomplete markets. Based on this discussion we suggest, in Section 5, some likely characteristics of strategic opportunities and the processes of their discovery, emphasizing the role of serendipity (which is not at all the same as pure luck). That observation leads to a discussion in Section 6 of the challenge of providing helpful prescriptive advice for the quest for strategic opportunity.

\section{Some Fundamentals}

In this section, we discuss basic conceptual issues relating to the terms "financial performance", "abnormal profitability," "resources", "markets" and "prices" or "values". The stance we take on these issues is, we believe, broadly appropriate for strategy research; specifically and more clearly, it is appropriate for the branch of strategy research that relies heavily on economic analysis. In any case, it defines the ground rules for the subsequent discussion in this paper.

Financial performance and profitability. In the strategic management literature, business success is generally equated with financial performance, and financial performance with "sustained abnormal profitability." We accept the first of these equations as fundamental to an economic analysis of strategy, and add the stipulation that, in the case of corporations, we are talking about the financial performance realized by shareholders. We have, however, serious reservations concerning the meaning and appropriateness of the second equation. The language of "sustained profitability" suggests both that the performance we should be concerned with is a flow concept - so much per period - and also that the duration of the flow is a uniquely important consideration. Neither of these suggestions is easily reconciled with basic economic principles. Financial markets typically provide abundant opportunities for transforming wealth stocks into income flows and vice versa. That being the case, it is presumably a second order consideration (at most) whether a wealth increase created by a business initially appears in the form of a one-time gain or of the establishment of a claim on a flow extending into the future. Considerations of capital market imperfection, stock market efficiency, tax law, and --we are recently reminded-- accounting rules are in practice significant for these transformations, but they are hardly substantial enough to legitimate an exclusive focus on flow profitability.

The notion of "sustainability," is, on the face of it, relevant only to the flow version of profitability. It is true, of course, that a longer stream of excess returns has a greater net present value (NPV); in that sense a sustainable success is more desirable, other things equal. Similarly, a higher rate of excess return, or a larger asset base on which the return is earned, is more desirable. While there are clearly important strategic issues associated with the challenge of

links between the general problem of sustainable advantage and the valuation issues that Barney raised. Some notable early contributions were those of Barney (1986), Dierickx and Cool (1989), and reply by Barney (1989). More recent contributions include, for example, Makadok and Barney (2001). We have, therefore, a rich store of prior contributions on which to draw; indeed, we have only hinted here at how rich it really is. In developing our argument, we attempt to give due acknowledgment to many of these prior contributions and points of contact, but our coverage is far from exhaustive. For the sake of the clarity and brevity of the argument, we forbear to explore the many interesting and relevant side trails that the literature suggests. 
sustaining a profitable position over a longer period of time, there is no particular reason to grant these considerations a distinctive place relative to considerations bearing on the other two dimensions of a positive NPV opportunity. ${ }^{3}$

Our view is that net present value - or expected net present value, where risk is involved - is the basic measure of success in the quest for strategic opportunity. It is "basic" in the sense that it stands at the limit set by Einstein's famous dictum that "everything should be made as simple as possible, but not simpler." It is possible to employ more general or sophisticated measures than NPV, and to invoke NPV in more sophisticated ways. It is difficult to make basic economic sense with a simpler analytical apparatus than the NPV concept provides. Hence, our discussion of "strategic opportunity" relates to opportunities for positive NPV undertakings, with merit understood to be measured by the amount of NPV.

In taking this "basic" economic approach, we set aside some considerations, such as organizational survival, which might make something other than the NPV of an isolated opportunity matter to management. We also set aside more important complications associated with the long-term interdependencies among opportunities that arise from, and affect the development of, the same set of underlying capabilities and competences.

Resources and resource valuation. From the start, it has been clear that the concept of "resources" in the resource-based view is extremely expansive. ${ }^{4}$ This expansiveness and flexibility has contributed to the success of the RBV, since it leaves diverse researchers free to operationalize the concept of resources in ways they consider appropriate for their particular undertakings. The expansiveness of the concept can, however, give rise to confusion where resource valuation is concerned. This hazard can be reduced by making a key distinction within the broad concept of resources.

The class of "resources" includes objects that are considerably more complex than the sorts of assets that are typically traded, though it clearly includes the latter as well. Accordingly, let "commodity resources" refer to the sorts of roughly standardized assets typically traded in identifiable markets -- the sorts of resources where there exist many units that are at least rough functional substitutes for each other - bushels of wheat, a super-computer, years of Ph.D. chemist time, an urban street corner in a high-traffic area. The complementary subclass of "complex resources" would include, by contrast, teams with lots of experience working together, factory buildings with permanent fixtures and diverse types of equipment that are costly to move, customized pieces of equipment derived from standardized ones by physical modifications that are costly to reverse. As these examples suggest, complex resources are typically created by bringing together commodity resources and, in effect, sinking some costs that have the effect of modifying them or connecting them to each other in ways that are at least semi-irreversible. Economically speaking, the connection makes productive performances possible with the complex resource that is not possible for the commodity resources individually. A rival firm that would like to have the advantages of the complex resource therefore has a choice between a) buying or hiring the constituent commodities and trying to build the resource itself, or b) buying

\footnotetext{
${ }^{3}$ The emphasis on flow profitability is most misleading when the flow itself is an artifact of accounting conventions, such as valuing assets at historical cost - or at zero, because they were expensed. This point has been argued elsewhere (Winter 1995).

${ }^{4}$ See Wernerfelt 1984, whose definition extends even to disadvantageous attributes. The one thing that is quite clear about resources is that they are firm-level attributes — abandon that, and the whole point of the RBV is lost.
} 
or hiring the whole thing from a firm that already possesses it - or at least, a big enough piece of the whole thing so that the fruits of the previous owner's "connection" investments are largely captured.

The distinction just developed has important implications for resource valuation. For commodity resources, it is reasonable to say that a market exists and that a price is at least roughly determined in that market. True, the resources in a category like urban street corners are not homogeneous; it takes substantial expertise to be a competent trader -- but relevant comparisons are in fact possible, and the expertise to make them exists in many individuals or firms.

Complex resources, by contrast, tend to be heterogeneous in a more significant way; individual examples may even be "unique." Such resources are idiosyncratic to a degree that makes valuation problematic. Idiosyncrasy arises from various sources, the most elementary being the paucity of examples within a class of rough functional substitutes and a short history of transacting in such things. The paucity of examples is partly a mathematical implication of the character of complex resources as combinations of commodity resources; the number of possible combinations is large. Beyond that, idiosyncrasy arises from long and path-dependent processes of resource creation (Levinthal 1997), in which an accumulation of contingencies and choices made under uncertainty can lead to major differences in the results of similarly-intentioned creation attempts. Finally, complex resources often have some attributes that are hidden from external observers/ potential buyers, and some may be hidden from owners/ potential sellers as well. Both information asymmetry and symmetric ignorance are prevalent - the latter contributing to the potential buyers' concern that the former may exist. All of these considerations imply thin, highly imperfect markets for strategic resources when indeed there are markets at all (Akerlof 1970, Dierickx and Cool 1989).

These considerations do not, of course, rule out a purely cost-based approach to valuation. With some effort it is possible to measure the investment involved in the creation of a particular complex resource, although the result is partly determined by luck. Cost data, however, clearly cannot answer by themselves the question of what the resource is worth. The demand-side information is missing.

\section{Market Completeness and Strategic Search}

Following Barney's terminology (Barney 1986), an efficient strategic factor market can be defined as a market where there would be no arbitrage opportunities to be gained by acquiring some combination of resources and selling this combination for a higher price than the cost of the individual resources. Rather, the price of each resource would reflect its value in all possible uses. In an exchange economy without markets such a condition would seem to require omniscience: there has to be someone who has considered the value of each resource in all possible uses. However, one of the main theoretical claims for the price system is precisely that such knowledge is not required (Hayek, 1945). Specifically, even if knowledge is decentralized and each agent only knows about the possibility of some transformations, prices emerging from competitive equilibrium will reflect the value of goods in their best use (Koopmans 1957).

The efficiency properties that are theoretically established for competitive markets, however, depend on those markets being complete (Debreu 1959). At the formal level, completeness demands not only that every commodity in the system has a corresponding market and market price, but more, that every interaction among the agents of the system must be represented by some commodity so that it may be mediated by markets. When this is 
(hypothetically) the case, the prices determined by competitive markets preclude any arbitrage opportunities. In reality, however, markets are massively incomplete (Stiglitz, 1993). Even in the case of familiar types of assets, markets do not exist in the full profusion that economic theory contemplates, with distinctions fully made according to date of availability and "state of the world". Markets are more dramatically lacking for most potential products and services, including the innumerable types of complex resources that could be created out of existing resources.

As emphasized by recent contributions, such incompleteness has important consequences for the efficiency of competitive prices (Makowski and Ostroy 1995; Matsuyama 1997) and for the possibility of successful strategic search. In particular, goods with a positive price in an economy with complete markets may have zero prices in an economy with incomplete markets and decentralized knowledge (Makowski and Ostroy, 1995). The simplest way to illustrate this is to perform a thought experiment in which we arbitrarily remove a subset of all existing goods and recalculate equilibrium prices. Suppose we withdrew Southwest Airlines. That is, we imagine that Southwest Airlines does not exist and thus that its demand and supply vectors are not incorporated in the calculation of the competitive equilibrium. A competitive equilibrium without Southwest Airlines would differ substantially with respect to the prices of several resources, such as gates at smaller airports and perhaps also hotels and infrastructure around smaller airports.

Of course, if someone realized that these resources might command a high price due to possibility of executing a strategy like that of Southwest Airlines, their prices would still remain high even if markets were incomplete. But there is a huge difference between theory and reality with respect to the information that underlies this result. In the theoretical model with complete markets, resource owners would not need to know why and in what way resources would ultimately be valuable for consumers to realize their value. Prices in competitive markets would communicate this information (Hayek, 1945). As a result, in complete markets, simple profit calculations based on existing prices would suffice for locating profitable opportunities (Koopmans 1957). In incomplete markets, however, there can be no guarantee that profit calculations based on price signals will identify the set of valuable opportunities (Makowski and Ostroy, 1995). Price signals would only be sufficient if all untraded goods were useless and thus had no effect on the prices of traded goods. While it is undoubtedly true that many currently untraded goods are probably useless, in incomplete markets this cannot be guaranteed unless there is somebody who has examined and rejected every possible use of these goods. For the innumerable bad ideas as well as for the occasional good opportunities, actors typically need to look beyond the price system in an effort to fill out their assessments of their prospects.

The proposition that truly deserves a serious claim on our attention, and that Barney correctly highlighted, is much weaker than the claim that the market always has the price right. It says that existing resources are correctly valued in relation to their existing uses. If that is the case, then valuable strategic opportunities cannot be found unless some element of novelty is introduced into the situation - either new resources, or new uses for existing resources; since the latter usually involves the creation of new complex resources it is typically the same thing as the former. There are reasons to quibble even about this weaker claim, but the quibbles are nothing compared to the objections to the radical extension of the claim to all resources. We will therefore set the quibbles aside and stipulate: in the absence of an element of novelty in the creation and use of resources, strategic opportunities that yield an abnormally high return do not exist. 
We should not, however, fall into the trap of presuming that the required novelty is necessarily some new-to-the-Earth technical innovation. Coordination failure caused by incomplete markets means that opportunity can inhere in novel combinations of existing resources, even if all the pieces remain familiar in their new relationship to each other. It is this fact that makes the image of an "arbitrage opportunity" valuable in the strategy context sometimes the opportunity remains available not because the arbitrage is complex per se, or because of a lack of inventive genius, but because its feasibility was simply hidden by market incompleteness. Schumpeter was on target with his broad characterization of innovation as "new combinations" and his inclusion of new ways of organization in his list of types (Schumpeter 1934).

Now novelty, per se, is cheap. The world of "unactualized possibles"(Quine 1961, chapter 1) is always very large, and it doesn't take much to actualize some of them. Hence, meeting this necessary condition for the existence of valuable strategic opportunities is not really a problem. The real problem is that any such valuable opportunities are needles in a haystack of mistakes, and they are hard to locate. But that is not the same thing as saying that they do not exist, or that searching for them is somehow an ex ante breakeven proposition regardless of the search methods applied or the attributes of the searcher.

In summary, a realistic appraisal of market systems compels recognition that markets are incomplete, and drastically so in the domain of currently untried activities. As a result, since the value of existing activities may depend on untried activities, it cannot be guaranteed that existing activities are priced correctly. Thus, when markets are incomplete, the prices prevailing in an apparent equilibrium do not preclude the existence of valuable unexploited opportunities. To exclude strategic arbitrage, a much stronger condition than market-clearing prices is necessary we might call it "exhaustive entrepreneurship." It would have to be that for each good, traded or untraded, there has to be someone who has considered the value of this good in all possible uses. As discussed in the next section, such a condition imposes a massively implausible information requirement on the actors in the system. Moreover, although actors can probably learn to identify the value of some of these resources, we argue that the local and decentralized character of the learning process implies that certain strategic opportunities are likely to remain. The challenges of the learning process also suggest some clues about the likely characteristics of such remaining opportunities.

\section{Valuation of Complex Resources: The Challenge of Imputation}

To illustrate the challenges of valuation in the absence of price guidance and the limits to "exhaustive entrepreneurship", we consider a simple example of a multistage production chain with several intermediate goods, as depicted in Figure 1. In this example, there are two basic commodities that can be transformed into two complex resources, which, in turn, eventually can be transformed into a specific consumption good. For simplicity, we assume that all transformations only require the use of undifferentiated labor. If a unit of labor can be bought at a price of $\mathbf{W}$, the cost of transforming one unit of a resource $\mathbf{i}$ into one unit of a resource $\mathbf{j}, \mathbf{C}_{\mathbf{i}, \mathbf{j}}$ is then $\mathbf{W} \mathbf{L}_{\mathbf{i}, j}$, where $\mathbf{L}_{\mathbf{i}, j}$ is the units of labor required to transform one unit of resource $\mathbf{i}$ into one unit of resource $\mathbf{j}$. We assume that all prices are in present value terms, so that profitability calculations are automatically NPV calculations. Finally, we assume that one unit of the consumption good can be sold in a competitive market at a price of $\mathbf{P}$.

In this simple economy, what is the "value" of complex resources, such as resource \#4? According to the "full imputation" principle in economics (Triffin 1949; Winter 1987), a proper economic valuation of a resource would be one that precisely accounts for the returns that this 
resource makes possible. In this example, this principle implies that the "value" of one unit of a resource is the maximal revenue that could be obtained by transforming one unit of this resource into other resources and eventually into the consumption good.

Calculating this value is easy for a resource $\mathbf{i}$ that can be directly transformed into the consumption good, i.e., into resource \#1. In this case, its value, $\mathbf{V}_{\mathbf{i}}$, is simply $\mathbf{P}-\mathbf{C}_{\mathbf{i}, \mathbf{1}}$. To calculate the value of resources that cannot be directly transformed into the consumption good, however, we must identify the maximal revenue that could be obtained by transforming this resource into alternative resources that, in turn, are transformed into the consumption good. For example, resource \#4 could be transformed both into resources \#2 and \#3. The revenues that could be obtained in both of these alternative transformations need to be compared to identify the value of resource \#4. More generally, to calculate the value, $\mathbf{V}_{\mathbf{i}}$, of a resource $\mathbf{i}$ we need to find the maximum of $\mathbf{P}-\Sigma \mathbf{C}_{\mathbf{k}, \mathbf{j}}$ for all possible sequences by which this resource could be transformed into the consumption good, where the $\mathrm{k}, \mathrm{j}$ pairs define a sequence like $(\mathrm{i}, 5),(5,2),(2,1)$.

Both computationally and conceptually it is useful to formulate this problem within a dynamic programming framework. In this formulation, the objective is to find the most valuable transformation of a given resource. To find this, we need to consider both the immediate costs of transformation, $\mathbf{C}_{\mathbf{i}, \mathbf{j}}$, and the value of the resources produced, directly and indirectly. If we define $\mathbf{V}_{\mathbf{i}}$ as the value of resource $\mathbf{i}$, it then follows from the principle of optimality in dynamic programming (Bellman 1957), that the value of any resource $\mathbf{i}$ must satisfy the following equation system

$$
\begin{aligned}
& \mathbf{V}_{\mathbf{i}}=\max _{\mathbf{j}}\left\{-\mathbf{C}_{\mathbf{i}, \mathbf{j}}+\mathbf{V}_{\mathbf{j}}\right\}, \quad \mathbf{i}=2,3, \ldots, \mathbf{j}=1,2,3, \ldots \\
& \mathbf{V}_{\mathbf{1}}=\mathbf{P}
\end{aligned}
$$

Here the maximum is taken over all possible resources $\mathbf{j}$ that the resource $\mathbf{i}$ can be transformed into. As is typical in dynamic programming, the solution to the problem for a particular starting point entails its solution for all possible starting points.

It can be shown (e.g., Bather 2000) that there are values $\mathbf{V}_{\mathbf{i}}, \mathbf{i}=2,3, \ldots$, that constitute the unique solution to this system of equations. In practice, the solution to this system of equations is found by backwards induction. Given that we know the value of the consumption good, $\mathbf{V}_{\mathbf{1}}=\mathbf{P}$, we can find the values of all resources \#2 and \#3, which can be directly transformed into the consumption good by computing $\mathbf{V}_{\mathbf{2}}=\mathbf{P}-\mathbf{C}_{\mathbf{2}, \mathbf{1}}$ and $\mathbf{V}_{\mathbf{3}}=\mathbf{P}-\mathbf{C}_{\mathbf{3}, \mathbf{1}}$. Using the recursive equation (1), the values of the resources that can be transformed into \#2 and \#3, i.e., \#4 and \#5, can then be found by finding the maximum of $-\mathbf{C}_{\mathbf{4}, \mathbf{j}}+\mathbf{V}_{\mathbf{j}}$ and $-\mathbf{C}_{\mathbf{5}, \mathbf{j}}+\mathbf{V}_{\mathbf{j}}$ for $\mathbf{j}=2,3$. Note that this procedure and the above equations would be formally identical if the costs or the price of the consumption good were stochastic. In this case, $\mathbf{C}_{\mathbf{i}, \mathbf{j}}$ and $\mathbf{V}_{\mathbf{i}}$ should simply be interpreted as expected values.

We think of this as the calculation of an entrepreneur considering a course of action, and the question is how the prices relate to the market prices he sees. It is clear that if market prices were identical to the values computed in the above way, the strategic factor market would be efficient in the sense that there could be no profit obtained by acquiring some resources and employing them in this particular alternative use. Rather, in this scenario the price of a resource would precisely account for the maximal revenue that a unit of this resource would make possible in all conceivable usages. Market prices would correspond to the principle of full imputation. This also implies that the profit that could be gained by acquiring any resource, transforming it into another resource, and selling the output would be zero (or less). To see this, notice that the equation $\mathbf{V}_{\mathbf{i}}=-\mathbf{C}_{\mathbf{i}, \mathbf{j}}+\mathbf{V}_{\mathbf{j}}$, which holds for the most profitable transformation of $\mathbf{i}$, can be rearranged as $\mathbf{V}_{\mathbf{j}}-\left(\mathbf{V}_{\mathbf{i}}+\mathbf{C}_{\mathbf{i}, \mathbf{j}}\right)=0$, which states the price that can be obtained for 
transforming $\mathbf{i}$ into $\mathbf{j}, \mathbf{V}_{\mathbf{j}}$, is equal to the cost of acquiring $\mathbf{i}$ and transforming $\mathbf{i}$ into $\mathbf{j}, \mathbf{V}_{\mathbf{i}}+\mathbf{C}_{\mathbf{i}, \mathbf{j}}$. Again, the same analysis holds if costs or the price of the consumption good were stochastic. In this case, expected profitability would be zero. Finally, if market prices corresponded to this ideal, no knowledge about the set of possible transformations in the economy would be required to identify the best use of a resource. Rather, an owner of resource $\mathbf{i}$ would simply need to compare the values of $-\mathbf{C}_{\mathbf{i}, \mathbf{j}}+\mathbf{V}_{\mathbf{j}}$ for all possible resources $\mathbf{j}$ that $\mathbf{i}$ can be transformed into. In other words, local, myopic profitability comparisons would be sufficient to identify the optimal use of a resource (Koopmans 1957).

On the other hand, if the entrepreneur's dynamic programming calculation results in values that differ from the market values, some opportunity for profit exists. Assuming this incentive leads to action, the apparent equilibrium will be broken. The full system is in equilibrium relative to existing entrepreneurial knowledge only when every entrepreneur, calculating in this way for every possible course of action, finds no profit opportunity.

Now, it can be demonstrated that equilibrium prices in complete markets, would correspond to the values computed in the above way (Dorfman, Samuelson and Solow, 1958). However, as discussed above, when markets are incomplete, market prices may not correspond to the values computed in the above way unless there are some individuals with knowledge about the value of resources. The necessary knowledge may be vast. For example, suppose that resources \#4 and \#2 are not traded. It is then clear that the market price of resource \#6 cannot be expected to reflect the value of transforming resource \#6 into \#4, and via resource \#2 into the consumption good. As discussed previously, only if some individual knew about the possibility of this transformation would this usage get reflected in the price of resource \#6. In other words, valuation in incomplete markets depends crucially on the knowledge economic agents have about alternative transformations. Although the discovery of alternative possibilities may be simple in this case, it is easy to imagine much more complex scenarios where resource \#6 could be transformed into many different, currently untraded, resources, which each could eventually be transformed into many other resources, etc.

To be capable of accurate calculations of this sort, an entrepreneur would require not only vast computational capacity but, more important, extensive knowledge of the transformations that are possible in the economy. Obviously, in many cases, individuals do not have immediate access to this knowledge. This raises the important question of how resources are valued in incomplete markets. In particular, when and for what types of resources can economic agents, on the basis of search and learning from experience, determine the value of resources and thus recognize any arbitrage opportunities? Formulated differently: when will the condition of "exhaustive entrepreneurship" be satisfied? Formally, this learning challenge is equivalent to the problem of learning to identify the value function of a large dynamic programming problem without initial knowledge of the set of possible transitions or the costs and rewards associated with each transition. In contrast to simple examples of experiential learning, such a learning problem has some special features that make it especially challenging (Samuel, 1959; Holland 1998; Sutton and Barto, 1998; Denrell, Fang and Levinthal 2002). In particular, as the above Bellman equations show, the value of a resource $\mathbf{i}$ depends on the value of the resources $\mathbf{j}$ that are possible to produce with $\mathbf{i}$. Formally, $\mathbf{V}_{\mathbf{i}}=\max _{\mathbf{j}}\left\{-\mathbf{C}_{\mathbf{i}, \mathbf{j}}+\mathbf{V}_{\mathbf{j}}\right\}$. Similarly, the values of the resources $\mathbf{j}$ depend on the values of the resources $\mathbf{k}$ that $\mathbf{j}$ can be transformed into, i.e., $\forall_{\mathbf{j}}: \mathbf{V}_{\mathbf{j}}=$ $\max _{\mathbf{k}}\left\{-\mathbf{C}_{\mathbf{j}, \mathbf{k}}+\mathbf{V}_{\mathbf{k}}\right\}$. This sequential interdependency implies that simple comparisons of the values of $-\mathbf{C}_{\mathbf{i}, \mathbf{j}}+\mathbf{V}_{\mathbf{j}}$, based on experience, will be misleading, unless $\mathbf{V}_{\mathbf{j}}$ are correctly assigned, which, in turn, requires that $\mathbf{V}_{\mathbf{k}}$ are correctly assigned, etc. 
Such sequential interdependency implies that identifying the value of certain types of resources, on the basis of experience, is very difficult. Consider, for example, the attempts of a firm to value a specific resource $\mathbf{i}$ in its possession. Even if this firm knows the value, as assessed by other firms in the economy, of employing resource $\mathbf{i}$ in alternative usages, this information may not be sufficient to derive the value of the resource. It is possible that if these other firms changed their production methods and valuations, resource $\mathbf{i}$ would be much more valuable.

The implication of this challenge of learning is that while individual firms might not see any possibilities for improvement in the way they use their resources, arbitrage opportunities may still exist that involve related changes in how several different resources are used. Resources that would only be valuable if the way in which existing resources are used changes substantially might be believed to be worthless. Only if all of these changes occurred simultaneously would the value of such a resource be discovered.

An illustrative metaphor for this path-dependent process of valuation is that of a search in a rugged landscape generated by all possible combinations of resource allocations (Kauffman 1993; Matsuyama 1997). Given the existing pattern of resource allocation, a firm might be able to spot an arbitrage opportunity involving an incremental change in the way certain resources are used. The pattern of resource allocation would thus be changed. This process will continue until no new arbitrage opportunities from incremental changes in the pattern of resource allocation can be spotted. However, the resulting equilibrium need not be a global optimum, or, more precisely, a Pareto optimum. Rather, to reach this optimum, it may be necessary to make large simultaneous changes in the pattern of resource allocation involving, perhaps, all economic agents. While such coordinated experiments could be imagined on a limited scale, they would obviously be infeasible as applied to large parts of the economy. ${ }^{5}$

\section{The Character of Strategic Opportunity}

The Architecture of Strategic Opportunities. Based on the above discussion of market incompleteness and the challenge of imputation, it is possible to say something about when and for what type of resources strategic opportunities may be located. As emphasized by Shleifer (2000), any systematic theory of market inefficiency, which simultaneously acknowledges the competitive forces that push markets towards efficiency, needs to answer when and why inefficiencies can occur and remain in the presence of competitive forces and the search for arbitrage opportunities.

The above arguments suggest that part of the answer lies in the complex, combinatorial, character of strategic opportunities. Specifically, it is unlikely that a valuable strategic opportunity can be seized simply by trading in existing resources. It is much more likely that a strategic opportunity can be found if the strategy involves trading in resources whose values are contingent upon one or several other resources being used in a new or different way, including the creation of novel types of complex resources. Unless several other actors have already recognized the opportunity and acted, resource values will not be aligned with the new uses. If

\footnotetext{
${ }^{5}$ This perspective on the process of valuation differs in important aspects from the discussion about the "market process" in Austrian economics (Kirzner 1973). In Austrian economics it is often argued that the activities of profitseeking entrepreneurs imply that there is a tendency for the economy to converge to an equilibrium in which no arbitrage opportunities exist. The underlying idea is that profit-seeking entrepreneurs will take advantage of arbitrage opportunities whenever they are observed. As a result, at least in a stationary economy without technological change, the supply of arbitrage opportunities will eventually be depleted. However, the above arguments suggest that this view is incomplete. Unless all resources, except for one, are used in their most valuable usages, it is not clear that arbitrage will lead the economy "closer" to a state in which no arbitrage opportunities, incremental or large, exist.
} 
these other resources are of an entirely different character or used by a completely different set of firms, identifying such an opportunity can be very challenging. Thus, there can be no presumption that this has already occurred.

This does not imply, however, that it would necessarily take a heroic effort to identify such opportunities. If a firm has preferential access to the missing piece of the puzzle, identifying the opportunity might be easy. ${ }^{6}$ In general, firms can be expected to differ considerably in the information they possess, even in the absence of deliberate effort to create the sorts of informational advantages that Barney referred to. Such differences in information - and differences in complementary assets - typically imply differences in positioning relative to new opportunities. Thus, in contrast to financial markets where blatant arbitrage opportunities are rare, we submit that the discovery of strategic opportunities is a normal occurrence in the product markets.

This characterization of strategic opportunities can also be used to shed some light on the debate between Dierickx and Cool (1989) and Barney (1989), regarding the issue of tradability and the strategic factor market argument. In the introduction of their article, Dierickx and Cool argued that there is an important set of resources, including a reputation for quality and expertise regarding complicated production processes, which cannot be bought and sold on any existing market. These examples are of course illustrative of what we have labeled "complex resources." In his response, Barney emphasized that tradability, per se, was not at issue. Rather, the point is that for any strategy to provide abnormal returns, the resources involved need to be acquired or developed at a cost that is lower than their eventual rent producing capacity. Although we agree with Barney on this point, we suggest that Dierickx and Cool's point is important for evaluating when resources could potentially be undervalued. Essentially, for the class of resources discussed by Dierickx and Cool, markets are incomplete. Moreover, the values of the complex resources discussed by Dierickx and Cool, such as corporate reputations, are typically contingent upon how other resources are used. For example, the value of the reputation of Southwest Airlines depends, to a large extent, on the idiosyncratic feature of the activities of Southwest Airlines. As emphasized above, in such situations, strategic opportunities are possible, although not guaranteed. Restated in this way, the argument of Dierickx and Cool suggests a class of resources whose values are very difficult to identify and thus could represent a strategic opportunity.

How Opportunities are Discovered. Given that a firm has found a strategic opportunity, what are the likely characteristics of the process by which it was discovered? The above discussion about the nature of strategic opportunities also has some implications for this question. Specifically, we argue that the character of the strategic opportunity implies that the process is likely to have been serendipitous, in the strict sense of that term. That is, success is a consequence of effort and luck joined by alertness and flexibility, where the effort was not initially directed to the specific end realized, alertness is required to recognize the lucky appearance of a new possibility and flexibility is displayed in re-directing t the effort.

In the strategy process literature several examples exist detailing how profitable strategies have emerged as a byproduct of activities with a different purpose rather than as an intended outcome of a deliberate search process (Mintzberg 1978). Consider, for example, the well-known story of how Honda entered and eventually came to dominate the market for small motorbikes in the United States. According to Pascale (1984), Honda's initial plan was to focus on large

\footnotetext{
${ }^{6}$ This might occur, for example, if the novelty extends the use of a previous innovation of the focal firm (see Winter 2000).
} 
motorbikes, which were considered to be more appropriate for the United States than the small motorbikes sold in Japan. However, when members of the staff used the small motorbikes for their own needs, comments from bystanders made them realize the potential demand for small motorbikes.

While such examples of accidental discovery may seem to be unlikely, we argue that the character of strategic opportunities implies that they should be expected in accounts of business success. More precisely, we argue that given that a strategic opportunity is only first discovered after some time, the discovery of this strategic opportunity is likely to have been serendipitous. The argument is that if there has been some search for strategic opportunities, the low-hanging fruits are likely to have been picked. It is therefore likely that the remaining strategic opportunities will likely consist of a complex combination of many commodities, or are otherwise hard to recognize. At the same time, the fact that the strategic opportunity was actually discovered suggests that it cannot have been too complex (Schoemaker 1990). It must have been possible, for at least some firm, to spot the opportunity without the need to combine the knowledge possessed by a wide variety of individuals.

These two observations suggest that the firm that did spot the opportunity must, for some reason, already have been in possession of several of the necessary components. The reason is the same as emphasized by Simon in his discussion of the evolution of complexity (Simon 1962, 1969). A complex system is unlikely to emerge if it requires that numerous elements are simultaneously combined. It is much more likely to emerge if it can be assembled via existing subsystems. In this case, the evolution of the system does not hinge upon the chance event that all necessary components emerged simultaneously in the right combination. Applied to the context of opportunity recognition, Simon's argument suggests that it is much more likely that an opportunity that requires a complex combination of commodities would be discovered if it could be assembled using subsystems that were already available since they were considered valuable by themselves. Also, it is more likely in proportion as more of those subsystems are known to a single firm.

At the same time, for the opportunity to still remain at a given date, the subsystems must either be unavailable or not considered valuable by most firms, or it would already have been discovered. Rather, it is likely that the necessary subsystems were only available to or considered valuable by the firm that discovered the opportunity. There are, at least, four possible reasons for this. First, only this firm had the strategic insight into the eventual value of these subsystems. Second, by deviating from existing practice, only this firm had the complementary set of activities that made these subsystems valuable. Third, this firm is "pre-adapted"; it was endowed with the subsystems by its previous history, for reasons unrelated to their application in the new opportunity (Cattani, 2002). Fourth, this firm made a mistake and thought that these subsystems were valuable by themselves even if all reasonable firms would agree that they were not. Although all of these reasons are possible, we suggest that the complex character of the strategic opportunity makes the first reason less likely than the others. Furthermore, although mistakes are not uncommon, we would argue that the second reason and third reasons are the most important.

Overall, this argument suggests that strategy process leading up to the discovery of a strategic opportunity is likely to have had the following characteristics. By deviating from existing practices, perhaps by intentionally choosing an unusual strategy or by necessity due to a lack of resources required to compete in the established manner, a firm develops a set of idiosyncratic resources. Although perhaps not very valuable by themselves, these resources 
could be used profitably in combination with other resources. By being the only firm with access to these components the firm is thus much more likely to discover the value of this combination.

What is the role of strategizing and intentionality in this story? According to the argument it is unlikely that the firm acquired most of the necessary components based on some vision of the value of the eventual combination. In this sense, the process of opportunity recognition is serendipitous, i.e., the opportunity was discovered as an unintended outcome of activities with another purpose. Nevertheless, it is likely that intentionality entered the story at some point in time. Specifically, when many of the necessary components were available to the firm, it is possible that the value of eventual combination could be foreseen. The process is analogous to an individual facing a jigsaw puzzle with only a few lacking pieces. Even if the individual did not have any idea of the final picture, and thus initially could not be guided by any picture of the final outcome, when most pieces were assembled he or she would nevertheless be able to guess the final picture and thus the color and pattern of the final pieces. In a similar way, when a firm has assembled many of the necessary components, it may be able to see that these resources could be valuable if complemented with some others. As a result, the search for the last components will be intentional rather than serendipitous.

This characterization also suggests that there may be little to learn from examining the strategy process of successful firms. At least for firms that discovered path-breaking strategic opportunities it is likely that they deviated from established practice by necessity or mistake rather than as part of a plan. To assemble the components required for spotting a path-breaking strategic opportunity, a firm needs to have assembled several components that individually are believed to be of little value. As a result, the firm needs to engage in an unusual amount of exploration. To be motivated to do so, a firm may need to be forced to adopt some of the elements or may need to adopt them by mistake (Denrell and March 2001). If this is so, the strategic opportunities of the most successful firms are likely to have developed through a process that it would be unwise to try.

The Role of Ex Post Limits to Competition. Using Peteraf's terminology, our focus so far has been on the limits to ex ante competition (Peteraf 1993). However, even if an individual is able to spot a strategic opportunity, exploiting the opportunity will not necessarily lead to positive NPV unless there are ex post limits to competition. Nevertheless, although ex post limits are necessary, it could be argued that in many cases the conditions for limited ex ante competition may be the most important.

First, to extract the rents made possible by a new combination of goods, this combination does not necessarily have to be protected by ex post limits to competition such as patents. As pointed out by Hirshleifer (1971), being in possession of unique information, the entrepreneur could potentially extract a large part of the rents by speculating in financial and product markets. Hirshleifer offers the example of Eli Whitney, the inventor of the cotton gin. The cotton gin had obvious speculative implications for the price of cotton, the value of cotton cropland, etc. Since Eli Whitney was the first in the know, Hirshleifer (1971) suggests that he possessed an "unparalleled opportunity for speculative profit" (p. 571). Although it is unclear whether such gains can always be obtained and if they would match the gains from obtaining a patent, this argument nevertheless suggests that isolating mechanisms are not necessary for the discoverer of a strategic opportunity to extract some part of the rents. ${ }^{7}$ Of course, in this case the discovery

\footnotetext{
${ }^{7}$ It is thus interesting that one of the tenets of the resource-based view, that isolating mechanisms are necessary for extracting the rents made possible by the discovery of a strategic opportunity, was refuted 15 years before the emergence of RBV.
} 
will not lead to sustained above normal returns, in the sense that the firm has above normal returns during the long period in which the cotton gin is used. Rather, the gains will be received almost immediately.

Second, in many cases where the above argument is inapplicable, being the first in the know may enable an entrepreneur to create limits to ex post competition. Thus, in this sense, ex post limits to competition may be a direct outcome of ex ante limits to competition. Several examples of such situations have been outlined in the literature, including investments in overcapacity to deter entrants (Dixit 1980) and tying up favorable locations and suppliers (Porter 1980). In these cases, ex post limits to competition are a direct implication of ex ante limits to competition and sustained competitive advantage would entirely be explained by the conditions for limited ex ante competition. This importance of this argument should not be exaggerated, however. As the empirical literature on first-mover advantages has shown, it is far from clear that the first-mover will come to dominate an industry or a product market (Teece 1987; Lieberman and Montgomery 1988; Chandler 1990; Vanderwerf and Mahon 1997; Lieberman and Montgomery 1998).

Even if both of these arguments do not apply, it still follows from the strategic factor market argument that any explanation of above average profitability is incomplete unless it is specified how the firm in question was able to acquire its resources for a price below their rent generating capacity. While ex post limits are sometimes necessary, they are never sufficient. This also implies that empirical hypotheses regarding when above average profitability is possible are incomplete if they only rely on the conditions for ex post limits to competition. To identify when a positive NPV opportunity exists one also needs to specify when strategic factor markets can be expected to be inefficient. The present paper is an initial attempt in this direction.

\section{Conclusions - and Tentative Prescriptions}

While the main focus of this paper is descriptive rather than normative, there are nevertheless some useful normative perspectives that follow from this analysis.

To be clear, we emphasize that we fully accept Barney's "bad news" message in relation to the likely results from purchasing existing resources and continuing them in their existing use (Barney 1986). In a quest for superior profitability, such an action is a simple bet on getting good luck in the form of a generous mistake by the seller and by possible rival bidders. While such mistakes can happen, the logic of the situation is that a "lemons"-type mistake by the buyer is more likely. We also accept that, in practice, the relevance of Barney's skeptical message reaches well beyond the narrow domain of simple asset transfers, and extends in particular to mergers and acquisitions. It is widely recognized that gains derived from synergies and efficiencies, regularly promised in the rhetoric of corporate acquirers and investment banks, are often times illusory - or over-compensated by the anti-synergies and diseconomies that weren't mentioned. What is curious is that this now-familiar, plausible and well-supported message seems eternally fresh to the investment community.

No doubt there are also many areas of potential activity where entrepreneurial scrutiny is sufficiently intense so that it is reasonable to assume that few valuable opportunities have gone unnoticed. The expected gains from further search in such areas may well be negative. This, however, can hardly be true generally: the range of things that have not been tried is simply too vast. If some areas are mined out, while in others the valuable claims are carefully staked and guarded, it is not because there is no virgin territory to search. It is because the searchers stay within the fences of their ideas, particularly their shared ideas. The farther we move from the 
domain of existing resources applied in existing uses, the less presumption there is that resources are in any sense correctly priced, or priced at all. Moreover, as we have shown, the shadow of pricing failure in remote regions is cast into the domain of existing resources, because it is only through application of existing resources that new ones can be created.

The crucial missing link between valuation and opportunity is the idiosyncratic information and capabilities of an individual firm. These are obviously relevant to the prospects for profitable trading in existing markets, but more importantly, to the firm's ability to create entirely new resources by some combination of resource purchase and application of resources it already has. Barney's brief discussion of the value of "organizational analysis" and "turning inwardly" (Barney 1986, p. 1239) touches on the issue, but seems to understate its scope and importance. It is partly a matter of "turning inwardly," but also a matter of looking outward at an unexplored environment from a particular vantage point on the frontier. The view of each firm is shaped by its own existing resources and information, including its ability to assess the resources of other firms, and is to that extent unique. The more distinctive the view, the more likely that such a view can encompass valuable opportunities not similarly visible to other firms - implying at least a temporary advantage for the firm that identifies the opportunity. Further, it is not at all the case that the view is static, since the environment is constantly changing - and so is the firm itself, in ways that condition what it can see and understand. In this sense, the flow of history continually renews each firm's ability to identify opportunities that are differentially suited to it, even without explicit effort to this end by the firm itself.

Combined with the above arguments, this suggests a theoretical reason why market inefficiencies that can be capitalized upon by a firm would tend to involve internal resources. Specifically, consider a firm with some set of idiosyncratic resources. If these resources are not traded, the value of other resources, available outside the firm, may not reflect their use in some combination of resources involving the idiosyncratic resources of this firm. Since this firm has privileged information about the existence of these resources, it follows that this firm may be the only actor who could spot this opportunity. As a result, through analysis of internal resources in relation to possible opportunities-- this firm may be able to spot a strategic opportunity where other resources can be bought for a price below their rent producing capacity. Analysis of only traded resources, however, is unlikely to turn up such strategic opportunities. Although such resources could potentially be used in more valuable combinations with the untraded resources of other firms, the firm does not have access to this information. In this sense, analysis of internal resources may be a necessary, or very likely necessary, component of a successful search for strategic opportunities. To the extent that managers are focused on analyzing the external opportunities without regard for whether such opportunities would involve internal resources, this analysis suggests a different focus for strategizing efforts.

Although this analysis implies that detailed strategic guidance is necessarily specific to the firm and its situation, the notion of serendipity does have some general prescriptive force. While good luck may befall the inert or lazy, serendipitous discovery occurs only in the course of an energetic quest - a quest in which lucky discoveries of an unanticipated kind can be recognized through alertness and then flexibly exploited.

This perspective on strategy is consistent with a large and growing body of evidence on the relationship of firm attributes to their entry decisions, innovations and other strategic moves, much of it recently reviewed by Helfat and Lieberman (2002) (see also Usselman 1993, Klepper and Simons 2000). In general, the evidence shows that opportunities are specific and firms that seize them are usually specifically prepared for them by their "pre-history". This mechanism is 
the counterpart of "pre-adapation" in biological evolution (Cattani 2002). Our perspective is also well aligned with the discussion by (Sarasvathy 2001) about the characteristics of the thought process used by entrepreneurs. Using verbal protocols from experienced entrepreneurs faced with a hypothetical venture problem, Sarasvathy (2001) demonstrated that the thought process of entrepreneurs is more likely to start from the givens of a situation and to proceed by investigating the possible effects and market opportunities that could be created with these means. Goal directed thinking, in which a market opportunity was identified at first and the means to achieve this opportunity were discussed later, was much less frequent.

The challenge of strategy is the challenge of assessing the opportunities that open to an idiosyncratically positioned actor in a changing environment. For this, the challenge of stock picking provides a poor analogy, because in that context actor idiosyncrasy plays a much smaller role. This assessment is clearly consistent with the central tenets of the RBV, but not with the discouraging words sometimes heard about resource pricing.

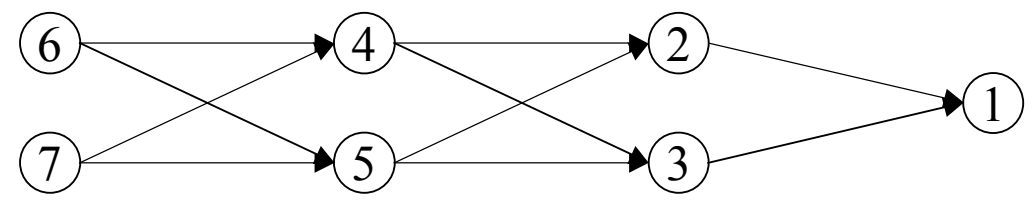

Commodities Complex Resources Complex Resources Consumption Good

\section{Figure 1}




\section{References}

Akerlof, G. A. (1970). "The market for 'lemons': Quality uncertainty and the market mechanism." Quarterly Journal of Economics 84(3): 488-500.

Barney, J. (1986). "Strategic factor markets: expectations, luck and business strategy." Management Science 32(October): 1231-1241.

Barney, J. (1989). “Asset stocks and sustained competitive advantage: a comment.” Management Science 35(December): 1511-1513.

Bather, J. (2000). An Introduction to Dynamic Programming and Sequential Decisions. Chichester, Wiley.

Bellman, R. (1957). Dynamic Programming. Princeton, Princeton University Press.

Cattani, G. (2002). Pre-adaptation, firm heterogeneity and technological performance: A study the evolution of optical communications, 1970-95. Philadelphia, Working Paper, The Wharton School.

Chandler, A. (1990). Scale and scope: the dynamics of industrial competition. Cambridge, MA, Harvard University Press.

Debreu, G. (1959). Theory of Value. New York, Wiley.

Denrell, J., C. Fang, and D. Levinthal (2002). From T-mazes to labyrinths: Learning from model-based feedback. Philadelphia, PA, Working Paper, The Wharton School.

Denrell, J, and J. March (2001). "Adaptation as information restriction: The hot stove effect"" Organization Science, 12(5): 523-538.

Dierickx, I. and K. O. Cool (1989). "Asset stock accumulation and sustainability of competitive advantage.” Management Science 35(December): 1504-1511.

Dixit, A. (1980). “The role of investment in entry-deterrence.” Economic Journal 90: 195-106.

Dorfman, R., P. A. Samuelson, et al. (1958). Linear Programming and Economic Analysis. New York, McGraw Hill.

Hayek, F. A. v. (1945). "The use of knowledge in society." American Economic Review 35: 519-530.

Helfat, C. E. and M. B. Lieberman (2002). "The birth of capabilities: market entry and the importance of pre-history." Industrial and Corporate Change 11: 725-760.

Hirschman, A. O. (1958). The Strategy of Economic Development. New Haven, Yale University Press.

Hirshleifer, J. (1971). "The private and social value of information and the reward to inventive activity." American Economic Review 61: 561-574.

Holland, J. (1998). Emergence: From Chaos to Order, Helix Books.

Kauffman, S. (1993). The Origins of Order. New York, Oxford University Press.

Kirzner, I. M. (1973). Competition and Entrepreneurship. Chicago, University of Chicago Press. 
Klepper, S. and K. L. Simons (2000). "Dominance by birthright: entry of prior radio producers and competitive ramifications in the U.S. television receiver industry." Strategic Management Journal 21: 997-1016.

Koopmans, T. C. (1957). Three essays on the state of economic science. New York, McGrawHill.

Levinthal, D. (1997). “Adaptation on rugged landscapes.” Management Science 43: 934-950.

Lieberman, M. B. and D. B. Montgomery (1988). "First-mover advantages." Strategic Management Journal 9: 41-58.

Lieberman, M. B. and D. B. Montgomery (1998). "First-mover (dis)advantages: retospective and link with the resource-based view." Strategic Management Journal 19: 1111-1125.

Makadok, R. and J. R. Barney (2001). "Strategic factor market intelligence: An application of information economics to strategy formulation and competitor intelligence." Management Science 47: 1621-1638.

Makowski, L. and J. M. Ostroy (1995). "Appropriation and efficiency: a revision of the first theorem of welfare economics.” American Economic Review 85(4): 808-827.

Matsuyama, K. (1997). "Economic development as coordination problems." The Role of Government in East Asian Economic Development. M. Aoki, H.-K. Kim and M. OkunoFujiwara, Eds. Oxford, Clarendon Press: 134-160.

Mintzberg, H. (1978). "Patterns in strategy formation.” Management Science 24: 934-948.

Pascale, R. (1984). "Perspectives on strategy: The real story behind Honda's success." California Management Review 26: 47-72.

Peteraf, M. (1993). "The cornerstones of competitive advantage: a resource-based view." Strategic Management Journal 14: 179-91.

Porter, M. E. (1980). Competitive strategy. New York, The Free Press.

Quine, W. V. O. (1961). From a Logical Point of View: Logico-Philosophical Essays. New York, Harper Torchbooks.

Sarasvathy, S. (2001). Efficient reasoning in expert entrepreneurial decisions: Existence and bounds, Academy of Management, Best Paper Proceedings.

Schoemaker, P. (1990). "Strategy, complexity and economic rent." Management Science 36: 1451-1463.

Schumpeter, J. (1934). The Theory of Economic Development. Cambridge, Harvard University Press.

Shleifer, A. (2000). Inefficient markets: An introduction to behavioral finance. Oxford, Oxford University Press.

Simon, H. A. (1962). "The architecture of complexity." Proceedings of the American Philosophical Society 106: 467-482.

Simon, H. A. (1969). The Sciences of the Artificial. Cambridge, MA, MIT Press.

Stiglitz, J. (1993). Whither Socialism? Cambridge, MA, MIT Press. 
Teece, D. J. (1987). "Profiting from technological innovation: implications for integration, collaboration, licensing and public policy." The Competitive Challenge: Strategies for Industrial Innovation and Renewal. D. J. Teece, Eds. Cambridge, MA, Ballinger.

Triffin, R. (1949). Monopolistic Competition and General Equilibrium Theory. Cambridge, MA, Harvard University Press.

Usselman, S. W. (1993). "IBM and its imitators: organizational capabilities and the emergence of the international computer industry." Business and Economic History 22(Winter 1993): 135.

Vanderwerf, P. A. and J. F. Mahon (1997). "Meta-analysis of the impact of research methods on findings of first-mover advantage." Management Science 43: 1510-1519.

Wattenberg, B. (1984). The good news is that the bad news is wrong.New York, Simon Schuster.

Wernerfelt, B. (1984). “A resource-based view of the firm.” Strategic Management Journal 5: $171-180$

Winter, S. G. (1987). "Knowledge and competence as strategic assets." The Competitive Challenge: Strategies for Industrial Innovation and Renewal. D. J. Teece, Eds. Cambridge, MA, Ballinger: 159-184.

Winter, S. G. (1995). "Four Rs of Profitability: Rents, Resources, Routines and Replication." Resource-Based and Evolutionary Theories of the Firm: Towards a Synthesis. C. Montgomery, Eds. Boston, Kluwer Academic Publishers.

Winter, S. G. (2000). "Appropriating the gains from innovation." Wharton on Managing Emerging Technologies. G. S. Day, P. J. H. Schoemaker and w. R. E. Gunther, Eds. New York, John Wiley: 242-265. 